\title{
RADIOLOGICAL INVESTIGATIONS, BIOCHEMICAL RENAL FUNCTION TESTS AND THE CHANGES AFTER SURGERY IN RENAL CALCULUS OBSTRUCTIVE UROPATHY
}

\author{
Mahesh Gupta1, Pawan Saini2, Pooja Gupta ${ }^{3}$, Manoj Gupta 4 \\ ${ }_{1}^{1}$ Associate Professor, Department of Surgery, Rama Medical College Hospital \& Research Centre, Mandhana, Kanpur, U. P. \\ ${ }^{2}$ Senior Resident, Department of Surgery, MMIMSR, Mullana, Ambala. \\ ${ }^{3}$ Consultant, Department of Medicine, SGL Charitable Hospital, Jalandhar. \\ ${ }^{4}$ Consultant, Department of Surgery, SGL Cheritable Hospital, Jalandhar.
}

\section{ABSTRACT}

Urolithiasis has affected the mankind for long years. These stones cause progressive renal impairment. These patients usually present with characteristic loin pain, vomiting, and sometimes fever. Patients may also be asymptomatic at times. Urinary stones can be classified on the basis of their size, location, X-ray characteristics, aetiology, composition (Mineralogy) and risk groups for recurrent stone formation.

\section{AIMS AND OBJECTIVES}

To evaluate the Preoperative and postoperative radiological and biochemical changes in renal calculus obstructive uropathy in patients with cortical thickness of minimum $4 \mathrm{~mm}$.

\section{MATERIAL AND METHODS}

All patients who were admitted in Department of Surgery, Rama Medical College Hospital and Research Centre, Kanpur, UP with diagnosis of obstructive uropathy due to stone disease and operated upon were included in this study.

\section{RESULTS}

After 1 month and 3 months the relief in obstruction was studied by repeating the tests. It was found that urea, creatinine levels took about 3 months to get normalized. USG and IVP at 3 months showed complete normalization of hydronephrosis, however, at one month few cases still had hydronephrosis.

\section{CONCLUSION}

Urea, creatinine levels along with USG and IVP form the basis of detection and management of obstructive uropathy. CT scan has a definitive role in few cases where urea creatinine levels are on higher side. Renal scan is mandatory in the cases of delayed/nonfunctioning on IVP. Nephrectomy should not be done without assessment of renal function (\%) on renal scan. After definitive management of relief of obstruction by various methods, it takes about three months for normalization of kidney function.

\section{KEYWORDS}

Urea, Creatinine, Ultrasonography, Intravenous Pyelography, Renal Scan, Renal Stone.

HOW TO CITE THIS ARTICLE: Gupta M, Saini P, Gupta P, et al. Radiological investigations, biochemical renal function tests and the changes after surgery in renal calculus obstructive uropathy. J Evolution Med Dent Sci 2016;5(1):61-65,

DOI: $10.14260 /$ jemds/2016/15

\section{INTRODUCTION}

Urolithiasis is a major problem worldwide and can cause progressive renal impairment. These patients are either asymptomatic or may present with characteristic loin pain, vomiting, and sometimes fever. Urinary stones can be classified on the basis of their size, location, X-ray characteristics, aetiology, composition (Mineralogy) and risk groups for recurrent stone formation. ${ }^{1}$ Ultrasonography is used as primary modality in diagnosing this disease. A renal contrast study (Enhanced CT or Intravenous Urography) is indicated while planning treatment for a renal stone in addition to assess the function of the affected kidney. ${ }^{1-3}$

Biochemical investigations like urea, electrolytes and creatinine are used to assess the renal functions whereas whole blood examination and midstream urine microscopic culture and sensitivity are used to diagnose sepsis. ${ }^{4}$

Financial or Other, Competing Interest: None.

Submission 13-12-2015, Peer Review 14-12-2015,

Acceptance 30-12-2015, Published 04-01-2016.

Corresponding Author:

Dr. Mahesh Gupta,

Associate Professor

Dept. Surgery,

Rama Medical College Hospital \& Research Centre,

E-mail:gm982003@yahoo.co.in

DOI:10.14260/jemds/2016/15
Gamma-camera renography using I-hippuran or 99mTcDTPA objectively analyses the accumulation, transit and elimination of injected activity by each kidney to produce the well-known time-activity curves. The simple and non-invasive nature of the procedure has an added advantage and is used widely now-a-days. ${ }^{5}$ It is emphasized that stone analysis should be performed in all first-time stone formers. ${ }^{6}$ Nonsteroidal Antiinflammatory Drugs (NSAIDs) are the drug of choice in cases of renal colic.7-8

Urgent decompression of the system is necessary to prevent further complications in infected hydronephrosis either by placement of an indwelling ureteral catheter under anaesthesia or percutaneous placement of a nephrostomy catheter.8,9 The definitive treatment of the stone should be delayed until sepsis is resolved, which includes endourology techniques like Percutaneous Nephrolitholapaxy (PCNL), Ureterorenoscopy (URS), open and laparoscopic surgery, Extracorporeal Shock Wave Lithotripsy (ESWL). ${ }^{10-12}$ In our study we plan to evaluate the radiological and biochemical improvement in the renal function of patients who have undergone surgery for renal stones causing obstruction.

\section{MATERIAL AND METHODS}

This study was done in 40 cases who were admitted in Department of Surgery with obstructive uropathy due to renal 
and ureteric calculus in Rama Medical College Hospital and Research Centre, Kanpur, UP. As per proforma, patient's history, clinical examination, investigations and treatment was recorded with special emphasis upon the radiological and biochemical renal function status in per and post-operative periods.

All patients with diagnosis of obstructive uropathy due to stone disease were included and operated upon in this study whereas patients below 10 years and above 70 years, severely moribund patient, Septicemic patients, chronic renal failure and patients with known severe cardiac conditions were excluded from this study. Patients undergoing only decompression like PCN or stenting without definitive procedure were also excluded from this study. At the time of admission detailed history with signs and symptoms of all the patients were noted down and every patient was investigated for complete blood tests, blood urea, creatinine, calcium, microscopy and urine culture. Ultrasonography of abdomen, X-rays KUB and IVP were done. CT scan of the abdomen and renal scan was done in few cases only and postoperative improvement was assessed by similar biochemical investigations and ultrasonography done after 1 month, 2month and 3-month interval. IVP was performed after 3 months in every case during the follow-up.

\section{RESULTS}

It is observed that urinary calculi is most commonly seen in age groups between 31-40 years; 13 (32.5\%) followed by 5160 years; 10 (25\%), 21-30 years; 07 (17.5\%) \& 41-50 years; 5 (12.5\%). (Table 1). Majority of patients in present study were admitted with the chief complaints of pain $(100 \%)$ vomiting (37.5\%) burning micturition (25\%) and fever (20\%). (Table 2) Out of 40 patients $15(37.5 \%)$ had urea $>40 \mathrm{mg} / \mathrm{dl}$ Whereas 19 $(47.5 \%)$ had creatinine $>1.4 \mathrm{mg} / \mathrm{dl}$ in pre-operative period. (Table 3). This was followed by urea $>40 \mathrm{mg} / \mathrm{dl}$ in $15(37.5 \%)$ patients whereas $16(40 \%)$ had creatinine $>1.4 \mathrm{mg} / \mathrm{dl}$ in postOperative period after 1 month. (Table 4) Furthermore 7 $(17.5 \%)$ patients had urea $>40 \mathrm{mg} / \mathrm{dl}$ and $11(27.5 \%)$ patients had creatinine $>1.4 \mathrm{mg} / \mathrm{dl}$ after 3 months of treatment. Finally it was observed that $33(82.5 \%)$ patients had normal urea levels as compared to 25 (62.5\%)pre-operatively, similarly 29 $(72.5 \%)$ patients had normal creatinine levels as compared to $21(52.5 \%)$ pre-operatively (Table 5). P value pre and postoperative urea levels (3 month).

Urea pre: $36.09 \pm 9.41$

Urea post: $34.66 \pm 9.78$

$P$ value: 0.021

Which was not significant

$\mathrm{P}$ value pre and post-operative creatinine levels (3 month).

Creatinine pre: $1.12 \pm .51$

Creatinine post: $1.11 \pm .41$

$P$ value: 0.589

Which was not significant

$\mathrm{P}$ value for pre and post-operative urea level at 3 month was P-0.021 (Not significant).

$P$ value for pre and post-operative creatinine level at 3 month was P-0.589 (not significant).

On the basis of ultrasonography, 33 (82.5\%) patients had hydronephrosis pre-operatively and $4(10 \%)$ were having non obstructive calculus but these cases had hydronephrosis on IVP and thus were included in the study and after 1 month of treatment, $11(27.5 \%)$ patients had residual hydronephrosis whereas 21 (52.5\%) had normal kidneys. The number of normal kidneys increased to $32(80 \%)$ after 3 months with only $4(10 \%)$ cases having residual hydronephrosis.

IVP findings in Pre-Operative period suggested 22 (55\%) patients had hydronephrosis of right side, 10 (25\%) hydronephrosis on left side and $5(12.5 \%)$ patients had bilateral hydronephrosis; 2 (5\%) patients were without hydronephrosis; however, these patients had hydronephrosis on USG and they were also selected for the study. (Table 6) and these figures were reduced to $3(7.5 \%)$ patients with residual hydronephrosis on left side and $1(2.5 \%)$ on right side; 32 $(80 \%)$ had normal kidneys as compared to only 2 cases $(5 \%)$ in pre-operative period (Table 7). Out of all these cases, right pyelolithotomy was done in 22 (55\%) cases, left pyelolithotomy in 9 (22.5\%), right ureterolithotomy 3 (7.5\%), left ureterolithotomy 1 (2.5\%), right nephrolithotomy 3 (7.5\%), whereas stones passed after hydrotherapy in 2 (5\%) (Medical expense therapy) and D. J. Stenting was done along with other procedures in $28(70 \%)$.

\section{DISCUSSION}

Urinary stones appear in $0.1-0.5 \%$ of world population with relapse rate of about $80 \%$. Most of kidney stones appear between the age of 20 to 40 years and they may be solitary or multiple with $40 \%$ of patients having them bilaterally. ${ }^{13-16}$ In our study we found 28 (70\%) male and 12 (30\%) female patients and majority of these were between 20 to 40 years. Stone formation is usually a result of urinary super saturation and any variation in urine saturation grade, urine $\mathrm{pH}$ and the concentration of crystallization inhibitors can lead to urolithiasis. ${ }^{17,18}$ Clinical manifestations of urinary calculi are an episode of renal-ureteral colic or gross haematuria, sudden lumbar pain which may be accompanied by nausea and vomiting. ${ }^{19}$ Obstructive uropathy refers to the structural impedance to the flow of urine anywhere along the urinary tract leading to 'hydronephrosis and if treated early, it is a potentially curable form of kidney disease. ${ }^{20,21}$ Menon (1998) stated that a urinary calculus "Announces" its presence with an acute episode of renal or ureteric colic and urolithiasis create symptoms only when they become trapped in some segment of urinary tract. ${ }^{22}$

In our study it was found that pain i.e. renal, ureteric colic was the commonest complaint $40(100 \%)$ patients, vomiting $15(37.5 \%)$ patients, burning micturition 10 (25\%) and fever $8(20 \%)$ patients. The hematocrit is important to assess for anaemia related to chronic renal insufficiency and the WBC count suggests the possible inflammation or infection secondary to obstruction or neoplasm as a cause of the obstruction. ${ }^{23,24}$ Urea and creatinine levels are one of the most important predictor of renal change. M Hussain et al. (2012) found grossly deranged blood urea and creatinine levels at the time of admission in his study of 293 patients.

However, on post-operative evaluation, recovery was seen in 183 patients with urine volume of more than 2-8 liters/24 hours followed by 79 (33.2\%) with urine output of 1 2 liters while $38(15.8 \%)$ produced volume of less than 1 liter 16. In our study, 14 (35\%) patients had pre-operative urea level $>40 \mathrm{mg} / \mathrm{dl}$ and 17 (42.5\%) patients had creatinine level $>1.4 \mathrm{mg} / \mathrm{dl}$ and post operatively, after 3 months, it was seen that only $7(17.5 \%)$ patients had post-operative urea level $>40 \mathrm{mg} / \mathrm{dl}$ and only $11(27.5 \%)$ had post-operative creatinine level $>1.4 \mathrm{mg} / \mathrm{dl}$. Ultrasonography has become one of the most 
important tools for assessing urinary tract obstruction because it is rapid, cost effective, safe, sensitive and is the diagnostic modality of choice in pregnancy. ${ }^{17,25}$

Use of duplex Doppler ultrasonography allows determination of the renal resistive index (RI), [peak systolic velocity- lowest diastolic velocity]/peak systolic velocity. An $\mathrm{RI}$ in the obstructed kidney that is 0.1 greater than the contralateral kidney is considered significant enough to indicate obstruction. ${ }^{24,26}$ However, Heidenreich A (2002) in their study suggested that both plain X-ray KUB and Ultrasound should be performed in patients with suspected stone disease for identifying stone disease and also to exclude other pathology which may produce similar urinary symptoms.2,18 In our study, USG was done pre-operatively as well as post operatively after 3 months and it was found that residual hydronephrosis was present only in $4(10 \%)$ cases whereas $32(80 \%)$ cases had normal functioning kidney and 4 $(10 \%)$ cases had gross hydronephrosis with no improvement in the renal function and thus were subjected to nephrectomy.

Intravenous Urogram (IVU) has been the gold standard for the detection of ureteral obstruction. The significant difference in IVU compared with ultrasonography is that the IVU shows both increased anatomic detail and functional attributes of the urinary system. ${ }^{20}$ However, in view of nephrotoxicity of the contrast material, the usefulness of the test for patients already suspected of having obstructive nephropathy is questionable. ${ }^{25}$ In our study, IVP done after 3 months of treatment showed residual hydronephrosis on right side only in $1(2.5 \%)$ case and on left side in $3(7.5 \%)$ cases; 32 $(80 \%)$ cases had no hydronephrosis and $4(10 \%)$ cases were subjected to nephrectomy. CT scan equals the accuracy of the IVP in determining the presence of obstruction, but surpasses the IVP in terms of detecting the specific cause of the obstruction. ${ }^{1,16}$

In our study, CT scan was done in three patients as the urea creatinine were more $>2 \mathrm{mg} / \mathrm{dl}$ and in these patients IVP was not possible. MRI gives no added advantage over CT scan and it does not visualise the stones. ${ }^{26,27}$ Renal scan and diuretic renography are the most reliable techniques to quantitatively assess the split and total renal function in the presence of hydronephrosis. Moreover, a functional obstruction can also be differentiated from an anatomic cause. ${ }^{28,29}$ In our study, three cases which were non-functioning on IVP were subjected to renal scan. Dalrymple et al. (1998) used Unenhanced Computerized Tomography (CT) for the management of acute flank pain and found $95 \%$ sensitivity, $98 \%$ specificity and $97 \%$ accuracy in ureteric stones. ${ }^{30,31}$

Finlayson and Ackerman (1989) have compared the three modalities of treatment for urinary calculi. According to them, the decision strategy depends on equipments, type of stones, needs of patients and skill of surgeon. In their series $87 \%$ of patients were treated with ESWL while open surgery was required in $4 \%$ patients. ${ }^{32}$ In our study, right pyelolithotomy was done in 22 (55\%) cases, left pyelolithotomy in 9 (22.5\%), right ureterolithotomy 3 (7.5\%),left ureterolithotomy 1 (2.5\%), right nephrolithotomy $3(7.5 \%)$, whereas stones passed after hydrotherapy in 2 (5\%) (Medical expense therapy) and D. J. Stenting was done along with other procedures in $28(70 \%)$. It is reported in the literature that there is return of renal function when the kidney was salvaged if cortical thickness was adequate, even though pre-operative renography depicted poor renal function. ${ }^{33,15}$ Today, the emphasis is on saving as much of the functioning renal tissue as is possible.

\section{CONCLUSION}

Urea, creatinine levels along with USG and IVP form the basis of detection and management of obstructive uropathy. CT scan has a definitive role in few cases where urea creatinine levels are on higher side. Renal scan is mandatory in the cases of delayed/non-functioning on IVP. Nephrectomy should not be done without assessment of renal function (\%) on renal scan. After definitive management of relief of obstruction by various methods, it takes about three months for normalization of kidney function. Main objective of the surgeon should be to preserve the kidney function and nephrectomy should be done as a last resort when all other methods to salvage the kidney function are used.

\section{REFERENCES}

1. Sourtzis S, Thibeau JF, Damry N, Raslan A, Vandendris M, Bellemans M. Radiologic investigation of renal colic: unenhanced helical CT compared with excretory urography. AJR American journal of roentgenology 1999;172:1491-1494.

2. Heidenreich A, Desgrandschamps F, Terrier F. Modern approach of diagnosis and management of acute flank pain: review of all imaging modalities. European urology 2002;41:351-362.

3. Varma G, Nair N, Salim A, et al. Investigations for recognizing urinary stone. Urological research 2009;37:349-352.

4. Shine S. Urinary calculus: IVU vs. CT renal stone? A critically appraised topic. Abdominal imaging 2008;33:41-43.

5. Buck AC, Macleod MA, Blacklock NJ. The advantages of 99mTc DTPA (Sn) in dynamic renal scintigraphy and measurement of renal function. British journal of urology 1980;52:174-186.

6. Straub M, Strohmaier WL, Berg W, et al. Diagnosis and metaphylaxis of stone disease. Consensus concept of the National Working Committee on Stone Disease for the upcoming German Urolithiasis Guideline. World journal of urology 2005;23:309-323.

7. Engeler DS, Schmid S, Schmid HP. The ideal analgesic treatment for acute renal colic-theory and practice. Scandinavian journal of urology and nephrology 2008;42:137-142.

8. Ramsey S, Robertson A, Ablett MJ, Meddings RN, Hollins GW, Little B. Evidence-based drainage of infected hydronephrosis secondary to ureteric calculi. Journal of endourology/Endourological Society 2010;24:185-189.

9. Pearle MS, Pierce HL, Miller GL, et al. Optimal method of urgent decompression of the collecting system for obstruction and infection due to ureteral calculi. The Journal of urology 1998;160:1260-1264.

10. Bichler KH, Lahme S, Strohmaier WL. Indications for open stone removal of urinary calculi. Urologia Internationalis 1997;59:102-108.

11. Honeck P, Wendt-Nordahl G, Krombach P, et al. Does open stone surgery still play a role in the treatment of urolithiasis? Data of a primary urolithiasis center. Journal of endourology/Endourological Society 2009;23:1209-1212. 
12. Hruza M, Schulze M, Teber D, et al. Laparoscopic techniques for removal of renal and ureteral calculi. Journal of endourology/Endourological Society 2009;23:1713-1718.

13. Bartoletti R, Cai T, Mondaini N, et al. Epidemiology and risk factors in urolithiasis. Urologia Internationalis 2007;79 Suppl 1:3-7.

14. BD, MS, NN, SKS. Upper urinary tract stones and Ureaplasma urealyticum.

Indian J Med Res 1997;105:15-21.

15. Šerić V, Dutour-Sikirić M, Mihaljević I, Tucak-Zorić S, Babić-Ivančić V, others. Metabolic and physico-chemical urolithiasis parameters in the first morning urine. Collegium antropologicum 2009;33:85-92.

16. Hussain M, Ali B, Ahmed S, Zafar N, Naqvi SA, Rizvi SAH. Prediction of renal function recovery in obstructive renal failure due to stones. Journal-Pakistan Medical Association 1997;47:159-161.

17. Micelyte S, Glinskis G, Cekauskas $\mathrm{Z}$, et al. [Hydronephrosis in pregnancy: importance of urologic actions and their volume]. Medicina (Kaunas, Lithuania) 2002;38 Suppl 1:22-29.

18. Dretler SP. Ureteral stone disease. Options for management. The Urologic Clinics of North America 1990;17:217-230.

19. Tiselius HG, Ackermann D, Alken P, et al. Guidelines on urolithiasis. European urology 2001;40:362-371.

20. Pais VM, Strandhoy JW, Assimos DG. Pathophysiology of urinary tract obstruction. Campbell-Walsh Urology 9th ed Philadelphia, Pa: Sauders Elsevier 2007.

21. Chevalier RL, Klahr S. Therapeutic approaches in obstructive uropathy. Semin Nephrol 1988;18:652-658.

22. Menon M. Urinary lithiasis: etiology, diagnosis and medical management. Campbell's urology 1998.

23. Rahman M, Smith MC. Chronic renal insufficiency: a diagnostic and therapeutic approach. Archives of Internal Medicine 1998;158:1743-1752.
24. Spencer JA, Tomlinson AJ, Weston MJ, et al. Early report: comparison of breath-hold MR excretory urography, Doppler ultrasound and isotope renography in evaluation of symptomatic hydronephrosis in pregnancy. Clinical radiology 2000;55:446-453.

25. Koelliker SL, Cronan JJ. Acute urinary tract obstruction. Imaging update. The Urologic clinics of North America 1997;24:571-582.

26. Kawashima A, Glockner JF, King BF. CT urography and MR urography. Radiologic clinics of North America 2003;41:945-961.

27. Smith RC, Rosenfield AT, Choe KA, et al. Acute flank pain: comparison of non-contrast-enhanced CT and intravenous urography. Radiology 1995;194:789-794.

28. Zielonko J, Studniarek M, Markuszewski M. MR urography of obstructive uropathy: diagnostic value of the method in selected clinical groups. European radiology 2003;13:802-809.

29. Turkolmez S, Atasever T, Turkolmez K, et al. Comparison of three different diuretic renal scintigraphy protocols in patients with dilated upper urinary tracts. Clin Nucl Med 2004;29:154-160.

30. Dalrymple NC, Verga M, Anderson KR, et al. The value of unenhanced helical computerized tomography in the management of acute flank pain. The Journal of urology 1998;159:735-740.

31. Palmer JS, Elder JS, Palmer LS. The use of betamethasone to manage the trapped penis following neonatal circumcision. The Journal of urology 2005;174:1577-1578.

32. Finlayson B, Ackermann D. Overview of surgical treatment of urolithiasis with special reference to lithotripsy. The Journal of urology 1989;141:778-779.

33. Shapiro SR, Bennett AH. Recovery of renal function after prolonged unilateral ureteral obstruction. The Journal of urology 1976;115:136-140.

\begin{tabular}{|c|c|c|c|c|}
\hline Sl. No. & AGE & MALE & FEMALE & TOTAL \\
\hline 1 & $<20$ yr. & $1(2.5 \%)$ & $0(0 \%)$ & $01(2.5 \%)$ \\
\hline 2 & $21-30$ yr. & $6(15 \%)$ & $1(2.5 \%)$ & $07(17.5 \%)$ \\
\hline 3 & $31-40$ yr. & $8(20 \%)$ & $5(12.5 \%)$ & $13(32.5 \%)$ \\
\hline 4 & $41-50$ yr. & $4(10 \%)$ & $1(2.5 \%)$ & $05(12.5 \%)$ \\
\hline 5 & $51-60$ yr. & $5(12.5 \%)$ & $5(12.5 \%)$ & $10(25 \%)$ \\
\hline 6 & $>60$ yr. & $4(10 \%)$ & $0(0 \%)$ & $04(10 \%)$ \\
\hline TOTAL & \multicolumn{6}{|c|}{ Table 1: Age and Sex wise Distribution of cases } \\
\hline
\end{tabular}

\begin{tabular}{|c|c|c|c|c|c|c|}
\hline Sl. No. & AGE & PAIN & FEVER & VOMITING & B. MICTURITION & TOTAL \\
\hline 1 & $<20$ yr. & $01(0.4 \%)$ & $00(0 \%)$ & $00(0 \%)$ & $01(2.5 \%)$ & $02(5 \%)$ \\
\hline 2 & $21-30$ & $07(2.8 \%)$ & $02(5 \%)$ & $02(5 \%)$ & $01(2.5 \%)$ & $12(30 \%)$ \\
\hline 3 & $31-40$ & $12(30 \%)$ & $01(2.5 \%)$ & $07(17.5 \%)$ & $03(7.5 \%)$ & $23(57.5 \%)$ \\
\hline 4 & $41-50$ & $05(12.5 \%)$ & $00(0 \%)$ & $00(0 \%)$ & $01(2.5 \%)$ & $06(15 \%)$ \\
\hline 5 & $51-60$ & $11(27.5 \%)$ & $02(5 \%)$ & $04(10 \%)$ & $04(10 \%)$ & $21(52.5 \%)$ \\
\hline 6 & $>60$ yr. & $04(10 \%)$ & $03(7.5 \%)$ & $02(5 \%)$ & $00(0 \%)$ & $09(22.5 \%)$ \\
\hline T0TAL & \multicolumn{7}{|c|}{ 40 (100\%) } & $08(20 \%)$ & $15(37.5 \%)$ & $10(25 \%)$ & 73 \\
\hline
\end{tabular}




\begin{tabular}{|c|c|c|c|c|c|}
\hline $\begin{array}{l}\text { Sl. } \\
\text { No }\end{array}$ & AGE & UREA & & CREATININE & \\
\hline & & $\begin{array}{c}<40 \mathrm{mg} / \\
\mathrm{dl}\end{array}$ & $\begin{array}{c}>40 \mathrm{mg} / \\
\mathrm{dl}\end{array}$ & $<1.4 \mathrm{mg} / \mathrm{dl}$ & $\begin{array}{c}>1.4 \mathrm{mg} / \\
\mathrm{dl}\end{array}$ \\
\hline 1 & $<20$ yr. & $1(2.5 \%)$ & $0(0 \%)$ & $1(2.5)$ & $0(0 \%)$ \\
\hline 2 & 21-30 yr. & $6(15 \%)$ & $1(2.5 \%)$ & $4(10 \%)$ & $3(7.5 \%)$ \\
\hline 3 & $31-40 \mathrm{yr}$. & $6(15 \%)$ & $\begin{array}{c}7 \\
(17.5 \%)\end{array}$ & $6(15 \%)$ & $\begin{array}{c}7 \\
(17.5 \%)\end{array}$ \\
\hline 4 & $41-50 \mathrm{yr}$. & $3(7.5 \%)$ & $2(5 \%)$ & $2(5 \%)$ & $3(7.5 \%)$ \\
\hline 5 & $51-60 \mathrm{yr}$. & $6(15 \%)$ & $4(10 \%)$ & $6(15 \%)$ & $4(10 \%)$ \\
\hline 6 & $>60 \mathrm{yr}$. & $3(7.5 \%)$ & $1(2.5 \%)$ & $2(5 \%)$ & $2(5 \%)$ \\
\hline \multicolumn{2}{|r|}{ TOTAL } & $\begin{array}{c}25 \\
(62.5 \%)\end{array}$ & $\begin{array}{c}15 \\
(37.5 \%)\end{array}$ & $\begin{array}{c}21 \\
(52.5 \%)\end{array}$ & $\begin{array}{c}19 \\
(47.5 \%)\end{array}$ \\
\hline \multicolumn{6}{|c|}{$\begin{array}{l}\text { Table 3: Age wise Distribution of } \\
\text { Pre-Operative Urea Creatinine levels }\end{array}$} \\
\hline
\end{tabular}

\begin{tabular}{|c|c|c|c|c|c|}
\hline $\begin{array}{c}\text { Sl. } \\
\text { No. }\end{array}$ & SEX & HDN & & & NORMAL \\
\hline & & B/L & RT & LT & \\
\hline 1 & $<20 \mathrm{yr}$ & $0(0 \%)$ & $0(0 \%)$ & $1(2.5 \%)$ & $0(0 \%)$ \\
\hline 2 & $21-30$ & $2(5 \%)$ & $4(10 \%)$ & $1(2.5 \%)$ & $0(0 \%)$ \\
\hline 3 & $31-40$ & $1(2.5 \%)$ & $8(20 \%)$ & $4(10 \%)$ & $0(0 \%)$ \\
\hline 4 & $41-50$ & $0(0 \%)$ & $5(12.5 \%)$ & $0(0 \%)$ & $0(0 \%)$ \\
\hline 5 & $51-60$ & $1(2.5 \%)$ & $4(10 \%)$ & $3(7.5 \%)$ & $2(5 \%)$ \\
\hline 6 & $>60 \mathrm{yr}$ & $1(2.5 \%)$ & $1(2.5 \%)$ & $1(2.5 \%)$ & 0 \\
\hline \multicolumn{7}{|c|}{ TOTAL } & 5 (12.5\%) & $\mathbf{2 2}(\mathbf{5 5} \%)$ & $\mathbf{1 0}(\mathbf{2 5 \% )}$ & $\mathbf{2}(\mathbf{5} \%)$ \\
\hline \multicolumn{7}{|c|}{ Showing Pre-Operative IVP Findings } \\
\hline
\end{tabular}

\begin{tabular}{|c|c|c|c|c|c|}
\hline $\begin{array}{l}\text { Sl. } \\
\text { No. }\end{array}$ & AGE & UREA & & $\begin{array}{c}\text { CREATI } \\
\text { NINE }\end{array}$ & \\
\hline & & $\begin{array}{c}<40 \mathrm{mg} / \\
\mathrm{dl}\end{array}$ & $\begin{array}{c}>40 \mathrm{mg} / \\
\mathrm{dl}\end{array}$ & $\begin{array}{c}<1.4 \mathrm{mg} / \\
\mathrm{dl}\end{array}$ & $>1.4 \mathrm{mg} / \mathrm{dl}$ \\
\hline 1 & $<20$ yr. & $1(2.5 \%)$ & $0(0 \%)$ & $1(2.5 \%)$ & $0(0 \%)$ \\
\hline 2 & $21-30 \mathrm{yr}$. & $4(10 \%)$ & $3(7.5 \%)$ & $2(5 \%)$ & $5(12.5 \%)$ \\
\hline 3 & $31-40 \mathrm{yr}$. & $8(20 \%)$ & $\begin{array}{c}5 \\
(12.5 \%)\end{array}$ & $6(15 \%)$ & 7 (17.5\%) \\
\hline 4 & $41-50 \mathrm{yr}$. & $3(7.5 \%)$ & $2(5 \%)$ & $3(7.5 \%)$ & $2(5 \%)$ \\
\hline 5 & $51-60 \mathrm{yr}$. & $6(15 \%)$ & $4(10 \%)$ & $8(20 \%)$ & $2(5 \%)$ \\
\hline 6 & $>60 \mathrm{yr}$. & $3(7.5 \%)$ & $1(2.5 \%)$ & $4(10 \%)$ & $0(0 \%)$ \\
\hline \multicolumn{2}{|c|}{ TOTAL } & $\begin{array}{c}25 \\
(62.5)\end{array}$ & $\begin{array}{c}15 \\
(37.5 \%)\end{array}$ & $\begin{array}{c}24 \\
(60 \%)\end{array}$ & $16(40 \%)$ \\
\hline
\end{tabular}

\begin{tabular}{|c|c|c|c|c|c|}
\hline $\begin{array}{c}\text { Sl. } \\
\text { No. }\end{array}$ & AGE & HDN & & & NORMAL \\
\hline & & B/L & RT & LT & \\
\hline 1 & $<20 y r$ & $0(0 \%)$ & $0(0 \%)$ & $0(0 \%)$ & $01(2.5 \%)$ \\
\hline & & & & & \\
\hline 2 & $21-30$ & $0(0 \%)$ & $0(0 \%)$ & $1(2.5 \%)$ & $04(10 \%)$ \\
\hline 3 & $31-40$ & $0(0 \%)$ & $1(2.5 \%)$ & $0(0 \%)$ & $11(27.5 \%)$ \\
\hline 4 & $41-50$ & $0(0 \%)$ & $0(0 \%)$ & $0(0 \%)$ & $05(12.5 \%)$ \\
\hline 5 & $51-60$ & $0(0 \%)$ & $0(0 \%)$ & $1(2.5 \%)$ & $08(20 \%)$ \\
\hline 6 & $>60 \mathrm{yr}$ & $0(0 \%)$ & $0(0 \%)$ & $1(2.5 \%)$ & $03(7.5 \%)$ \\
\hline \multicolumn{6}{|c|}{ Totale 7: Age wise Distribution of Cases showing } \\
\hline \multicolumn{7}{|c|}{ Post-Operative IVP Findings after 3 Month } \\
\hline
\end{tabular}

\begin{tabular}{|c|c|c|c|c|c|}
\hline $\begin{array}{l}\text { Sl. } \\
\text { No. }\end{array}$ & AGE & UREA & & CREATININE & \\
\hline & & $\begin{array}{c}<40 \mathrm{mg} / \\
\mathrm{dl} /\end{array}$ & $\begin{array}{c}>40 \mathrm{mg} / \\
\mathrm{dl}\end{array}$ & $<1.4 \mathrm{mg} / \mathrm{dl}$ & $>1.4 \mathrm{mg} / \mathrm{dl}$ \\
\hline 1 & $<20$ yr. & $\begin{array}{c}01 \\
(2.5 \%)\end{array}$ & $00(0 \%)$ & 01 (2.5\%) & $00(0 \%)$ \\
\hline 2 & $\begin{array}{c}21-30 \\
\text { yr. }\end{array}$ & $\begin{array}{c}06 \\
(15 \%)\end{array}$ & $\begin{array}{c}01 \\
(2.5 \%)\end{array}$ & 05 (12.5\%) & $02(5 \%)$ \\
\hline 3 & $\begin{array}{c}31-40 \\
\text { yr. }\end{array}$ & $\begin{array}{c}12 \\
(30 \%)\end{array}$ & $\begin{array}{c}01 \\
(2.5 \%) \\
\end{array}$ & $08(20 \%)$ & 05 (12.5\%) \\
\hline 4 & $\begin{array}{c}41-50 \\
\text { yr. }\end{array}$ & $\begin{array}{c}03 \\
(7.5 \%)\end{array}$ & $02(5 \%)$ & $04(10 \%)$ & $01(2.5 \%)$ \\
\hline 5 & $\begin{array}{c}51-60 \\
\text { yr. }\end{array}$ & $\begin{array}{c}08 \\
(20 \%)\end{array}$ & $02(5 \%)$ & $08(20 \%)$ & 02 (5\%) \\
\hline 6 & $>60 \mathrm{yr}$. & $\begin{array}{c}03 \\
(7.5 \%)\end{array}$ & $\begin{array}{c}01 \\
(2.5 \%)\end{array}$ & 03 (7.5\%) & $01(2.5 \%)$ \\
\hline \multicolumn{2}{|c|}{ TOTAL } & $\begin{array}{c}33 \\
(82.5 \%)\end{array}$ & $\begin{array}{c}07 \\
(17.5 \%)\end{array}$ & 29 (72.5\%) & $\begin{array}{c}11 \\
(27.5 \%)\end{array}$ \\
\hline
\end{tabular}

